\title{
Trichinella in the North
}

\author{
Niina Airas ${ }^{1}$, Seppo Saari ${ }^{1}$, Taina Mikkonen ${ }^{1}$, Anna-Maija Virtala', Jani Pellikka', Antti Oksanen², Marja Isomursu², \\ Antti Sukura ${ }^{*}$ \\ From Parasite infections of domestic animals in the Nordic countries - emerging threats and challenges. \\ The 22nd Symposium of the Nordic Committee for Veterinary Scientific Cooperation (NKVet) \\ Helsinki, Finland. 7-9 September 2008
}

\section{Background}

Endemic human trichinellosis has been rare in Norway, Sweden and Finland. In Norway the last outbreak involving five persons is from 1953 and before that there were reported six epidemics with 711 patients since 1881 (reference in [1]). In Sweden 10 outbreaks involving 504 patients were documented 1917-1969 (reference in [2]). In Finland only eight human cases have been reported since 1890, the latest being three hunters at 1977 who got the infection from bear meat (reference in [1]).

Sporadic cases of trichinellosis in production animals have been detected in pig meat inspection in these countries. In Norway there was a peak of positive pigs in the 1950's and 1960's but since 1981 no positive finding in pigs has been reported. In Sweden, 127 positive pigs were reported 1970-1999 and no cases since 2000. The first infected Finnish pig was found 1954, and the total number of positive pigs in fifty years was up to 714 (1954-2003). There was a peak of cases in the 1980's and 90's when a total of 671 pigs were found positive. During 1981-2000, the positive animals originated from 0-19 farms yearly. Since 2004 no trichinella has been found in pigs. The decrease in Trichinella prevalence and incidence in domestic swine has been speculated to be due the change in Finnish swine industry since Finland joined the EU in 1995 [3]. During recent years, the industry has moved towards large-scale enterprises with corporative ownership with new facilities. These are better protected against the Trichinella infection commonly present in surrounding wildlife in Finland [3]. High sylvatic trichinellosis prevalence has been reflected to farmed wild boars in which condemnation due trichinelllosis has been relatively more common than in pig. To clarify the spatial variation of sylvatic trichinella

${ }^{1}$ Department of Basic Veterinary Sciences, Faculty of Veterinary Medicine, University of Helsinki, Helsinki, Finland

Full list of author information is available at the end of the article prevalence suggested in earlier studies, a new Finnish sample set was analyzed.

\section{Material and methods}

Muscle samples of 2487 carnivorous wild animals from eight host species during 1999-2005 were collected by volunteer hunters. Molecular identification was performed on larval isolates with multiplex PCR.

\section{Results}

Out of 2487 animals analyzed, Trichinella spp were revealed from 618 animals. Different host species showed variable sample prevalence (range: 0- $46 \%$ ). Almost half of the lynx harboured Trichinella spp (46\%); in species rank, lynx were followed by wolves (39\%), raccoon dogs (28\%), and red foxes (19\%). Lower than ten percent prevalences were detected in sampled pine martens, badgers, bears, and otters. No larvae were detected from mink. The overall Trichinella prevalence from all sampled host species was not geographically equally distributed varying from $2.6 \%$ (Lapland) up to $67 \%$ on different game districts $(\mathrm{P}<0.001)$, showing obvious diminishing gradient form south to north (figure 1).

Molecular analysis was performed with 328 larval isolates. Trichinella species were successfully identified from 303 animals, from 25 animals amplification did not give specific reaction (7.6\%). Four species were discovered: T. spiralis, T. nativa, T. britovi, and T. pseudospiralis. Single Trichinella species were revealed from 281 (93\%) of the infected host animals and $22(7 \%)$ showed mixed infections. T. nativa was the most common single species $(80.1 \%)$ followed by $T$. spiralis (12.8\%) T. britovi (6.0\%) and T. pseudospiralis (1.1\%), which was found in single infection in only three animals but in mixed infection in four more individuals. From mixed infections, never more than two different 

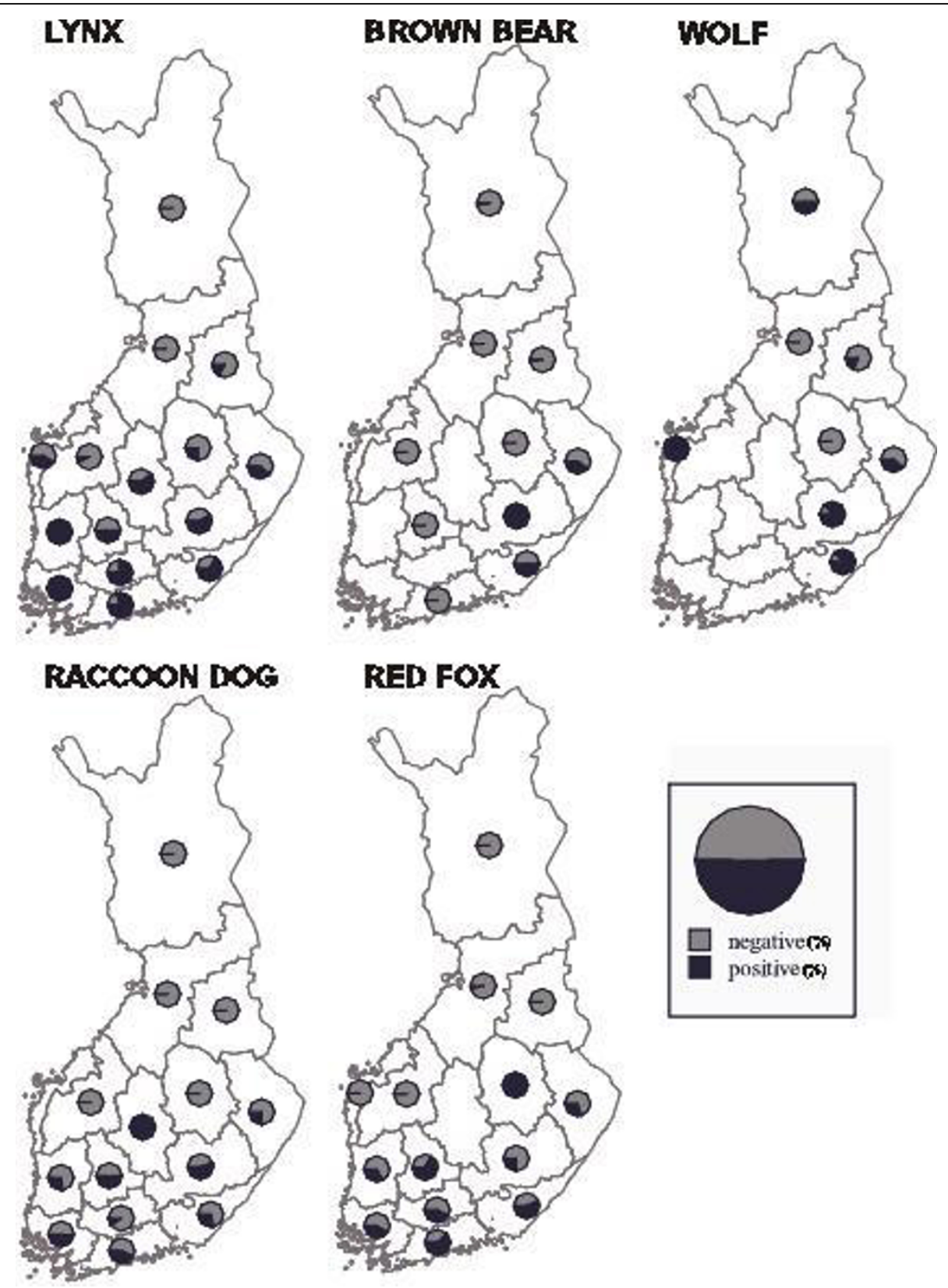

Figure 1 Prevalence gradient is seen in all sampled animal species with sample size over 100 individuals.

species were found, but all possible two-species combinations of four species were discovered. Species geographic distribution showed that all four species were discovered only from the southern part of the country; in the middle and northern part, only $T$. nativa and T. spiralis were revealed.

The parasite burden was not normally distributed. Different hosts showed variations in the infection density and also different Trichinella species made different parasite burdens. There was a significant interaction between animal species and Trichinella species showing for example that $T$. spiralis gave a higher larval burden in raccoon dog than in other animals. However, in raccoon dogs, the host specie with the highest burden, infection densities did not differ between infecting Trichinella species.

\section{Conclusion}

In Finland sylvatic trichinellosis is very common with big geographical differences showing clear diminishing along south to north gradient. T. nativa was the most prevalent species in the country but, remarkably, the 
domestic species T. spiralis was isolated from $15 \%$ of sylvatic isolations. T. spiralis was recovered all around in Finland. Intriguingly, T. spiralis was revealed form the very north in a fox in an area where never any domestic outbreak of trichinellosis has been reported, and seldom any swine has been seen, indicating that $T$. spiralis may exist in sylvatic cycle without external sources from synanthropic animals.

When population sizes are considered, the major reservoir animals in Finland are the raccoon dog and the red fox..

\section{Author details}

${ }^{1}$ Department of Basic Veterinary Sciences, Faculty of Veterinary Medicine, University of Helsinki, Helsinki, Finland. ${ }^{2}$ Finnish Food Safety Authority Evira, Oulu, Finland.

Published: 13 October 2010

\section{References}

1. Oivanen L: Endemic trichinellosis - experimental and epidemiological studies. Dissertation 2005, Yliopistopaino, Helsinki.

2. Pozio E, Christensson D, Steen M, Marucci G, La Rosa G, Bröjer C, Mörner T, Uhlhorn H, Ågren E, Hall M: Trichinella pseudospiralis foci in Sweden. Vet Parasitology 2004, 125:335-342.

3. Oivanen L, Oksanen A: Synanthropic Trichinella infection in Finland. Vet Parasitol 2009, 159:281-284

doi:10.1186/1751-0147-52-S1-S8

Cite this article as: Airas et al:: Trichinella in the North. Acta Veterinaria Scandinavica 2010 52(Suppl 1):S8.
Submit your next manuscript to BioMed Central and take full advantage of:

- Convenient online submission

- Thorough peer review

- No space constraints or color figure charges

- Immediate publication on acceptance

- Inclusion in PubMed, CAS, Scopus and Google Scholar

- Research which is freely available for redistribution

Submit your manuscript at www.biomedcentral.com/submit 